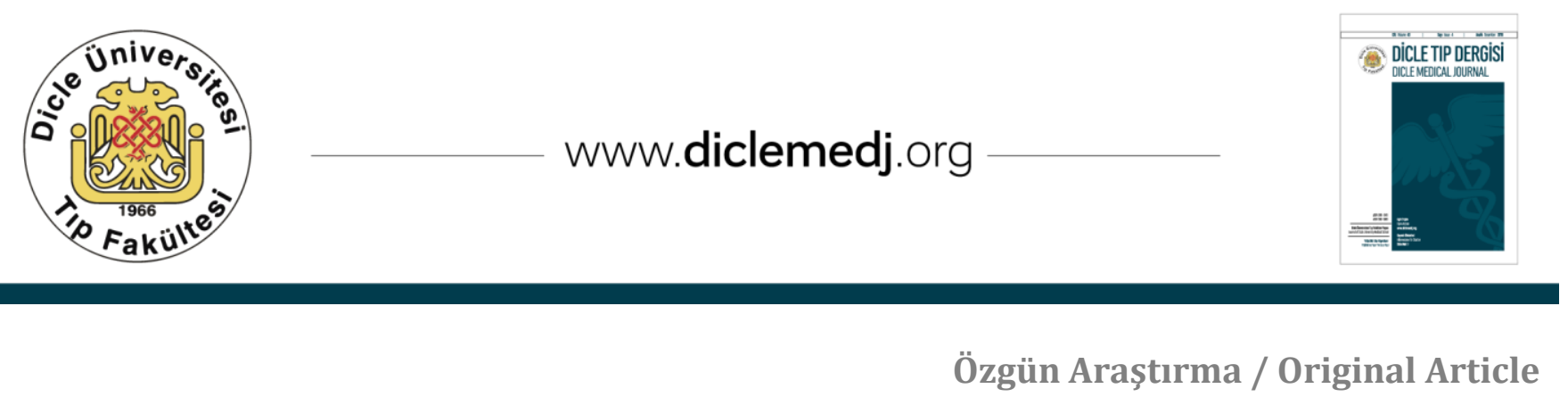

\title{
Bronşektazide Klinik Özellikler ve Cerrahi Tedavinin Sonuçları
}

\author{
Erdoğan Dadaş \\ Adlyaman Üniversitesi Tıp Fakültesi Göğüs Cerrahi Anabilim Dalı, Adlyaman, Türkiye ORCID: 0000-0001-7018-2274
}

Geliş: 20.11.2017; Revizyon: 08.03.2018; Kabul Tarihi: 22.03.2018

\section{Özet}

Amaç: $\mathrm{Bu}$ çalışma bronşektazili hastaların klinik özelliklerinin belirlenmesi ve cerrahinin sonuçlarının değerlendirilmesini amaçlamaktadır.

Yöntemler: Haziran 2012 - Haziran 2017 tarihleri arasında, Üniversitemiz Tıp Fakültesi Gögüs Cerrahisi Kliniği'nde cerrahi rezeksiyon uygulanan 18 (7 erkek, 11 kadın; ort.yaş 44 yıl; dağılım 14-68 yıl) bronşektazi hastasının tıbbi kayıtları retrospektif olarak incelendi. Hastaların takip verilerine telefon veya poliklinik kontrolleri ile ulaşıldı. Hastalar yaş, cinsiyet, semptomlar, tanı yöntemleri, lezyonun yerleşim yeri, yapılan ameliyat, morbidite, mortalite ve cerrahi tedavinin sonuçları açısından değerlendirildi.

Bulgular: En sık görülen semptom kronik öksürük ve balgam çıkarma idi. Sekiz hastada (\%44) sol akciğer tutulumu, 9 hastada (\%50) sağ akciğer tutulumu ve 1 hastada (\%6) iki taraflı akciğer tutulumu vardı. Bronşektazinin en sık etkilediği alan sol alt lob idi (n=6). On altı olguda (\%89) tam rezeksiyon, 2 olguda (\%11) tam olmayan rezeksiyon uygulandı. Tüm hastaların cerrahi tedavi sonuçlarına ulaşıldı. Ortalama takip süresi 30 (Dağılım:5-65) ay idi. 0n yedi hastada (\%95) tedavide başarı sağlanırken 1 olgu tedaviden yarar görmedi.

Sonuç: Bronşektazili hastalarda cerrahi tedavi \%95 başarı oranı ile iyi bir tedavi seçeneğidir. Hemoptizi gibi hayatı tehdit edici komplikasyonları kontrol altına alır, semptomlarda ve hayat kalitesinde tatmin edici düzelme sağlar.

Anahtar kelimeler: Bronşektazi; cerrahi rezeksiyon; cerrahinin sonuçları

DOI: $10.5798 /$ dicletip.410824

Yazışma Adresi / Correspondence: Erdoğan Dadaş, Adlyaman Üniversitesi Tıp Fakültesi Göğüs Cerrahi Anabilim Dalı, Adlyaman, Türkiye e-mail: erdogandadas@yahoo.com 


\title{
Clinic Characteristics and Results of Surgical Treatment in the Bronchiectasis
}

\begin{abstract}
Objective: This study aims to determine the clinical characteristics of the patients with bronchiectasis and evaluate the outcomes of surgery.

Methods: Medical records of 18 patients ( 7 males and 11 females; mean age 44 years; range, 14 to 68 years) with bronchiectasis who underwent surgical resection at Our University, Medical Faculty, Thoracic Surgery Department between June 2012 and June 2017 were retrospectively reviewed. Follow-up data of the patients were obtained by the telephone or outpatient control visits. Patients were evaluated according to the age, sex, symptoms, diagnostic methods, localization of lesion, surgery performed, morbidity, mortality and results of surgical treatment.

Results: The most frequent symptoms were chronic cough and sputum. Eight patients (45\%) had left lung involvement, 9 patients (50\%) had right lung involvement, and 1 patient (5\%) had bilateral lung involvement. The most affected region by bronchiectasis was the left lower lobe in 6 patients (33\%). Complete resection was applied to 16 patients (89\%), while incomplete resection was applied to 2 patients (11\%). Follow-up data of all patients were obtained. Mean follow-up period was 30 (Range: 5-65) months. While 17patients (95\%) were completely recovered, and in one $(5 \%)$ treatment failed.

Conclusion: In patients with bronchiectasis, surgical resection is a good treatment option with a success rate $95 \%$. It controls life-threatening complications like hemoptysis, provides satisfactory improvement in symptoms and quality of life.
\end{abstract}

Keywords: Bronchiectasis; surgical resection; outcomes of surgery.

\section{GíRIŞ}

Bronşektazi, solunum yollarındaki çeşitli mikroorganizmaların uygun olarak temizlenememesi ve tekrarlayıcı enfeksiyonlara bağlı olarak gelişen kronik bronşiyalenflamasyonun neden olduğu kalıcı hava yolu genişlemesidir ${ }^{1}$. Antibiyotik tedavisi, solunum fizyoterapisi (postüral drenaj), bronkodilatör ve mukolitik tedavi medikal/konservatif tedavi seçenekleridir. Bununla birlikte, medikal/konservafif tedaviye cevapsız, kistikfibrozis dışı bronşektazili hastalarda uygun tedavi seçeneği cerrahidir². Farklı yayınlarda, cerrahi tedavide mortalite oranları \%0-3,4 arasında verilmiştir ${ }^{3,4}$. Cerrahi sonrası uzun dönem sonuçları ile ilgili az bilgi vardır ${ }^{4} \mathrm{Bu}$ çalışmanın amacl, cerrahi tedavi uygulanan bronşektazi hastaları ile ilgili klinik ve cerrahi özellikler ile cerrahi tedavi sonuçlarımızı paylaşmaktır.

\section{YÖNTEMLER}

Haziran 2012 - Haziran 2017 tarihleri arasında, Üniversitemiz Tıp Fakültesi Göğüs Cerrahisi Kliniği'nde, cerrahi rezeksiyon uygulanan 18 bronşektazi hastasının medikal kayıtları retrospektif olarak incelendi. Hastalar, acil servis veya göğüs hastalıkları polikliniklerine müracaat etmiş ve gögüs bilgisayarlı tomografi (BT) ile radyolojik tanıları sağlanarak tarafımıza yönlendirilmiş olgulardan oluşmaktaydı. Tüm hastaların, hastalık öyküleri, fizik muayeneleri, hematolojik ve biyokimyasal incelemeleri yapıldı. Tüm hastalarda akciğer fonksiyon testleri ve akciğer fonksiyonları kısıtlı olan hastalarda akciğer perfüzyon sintigrafisi ile solunum rezervleri belirlendi. Birinci saniye zorlu ekspiratuvar volüm (FEV1) değeri 2 litre (lt) ve üzeri olan veya FEV1 değerinin beklenenin \%80'i olan ve egzersiz dispnesi olmayan hastalarda ilave bir solunum rezervi değerlendirilmesi yapılmadı (pnömonektomi dahil her türlü rezeksiyona uygun olarak kabul edildi). FEV1 değerinin 1.5lt 
ve üzerinde olması ve egzersiz dispnesinin olmaması lobektomi için yeterli kabul edildi. Yukarıdaki kriterlere uymayan hastalarda tahmini ameliyat sonrası FEV1 değerinin \%40 ve üzeri olması lobektomi için yeterli kriter idi. Hemoptizisi olan altı hastaya kanamanın tarafını ve lokalizasyonunu belirlemek için ayrıca bronkoskopi uygulandı. Pürülan balgam çlkaran hastalara 10 gün süre ile antibiyotik tedavi, mukolitikajan, bronkodilatatör, antienflamatuvar ve fizik tedavi uygulandı. Medikal/konservatif tedaviye rağmen yılda en az beş kez antibiyotik kullanmayı gerektiren akciğer enfeksiyonu geçirme, medikal tedaviye yanıtsız kronik öksürük ve balgam çıkarma, hemoptizi ve harap olmuş lob cerrahi endikasyonları oluşturmakta idi. Yeterli pulmoner ve kardiyak rezervin olması ve bölgesel tutulum cerrahiye uygunluk kriterlerimiz idi. Tüm hastalarda çift lümenli endotrakeal entübasyon tüpü kullanıldı.

Hastalarda arka-yan torakotomi uyguland. Bronşların aşırı diseksiyonundan kaçınıldı ve pnömonektomi yapılan hastalarda bronș güdükleri interkostal kas flebi ile desteklendi. Ameliyat sonrası 30 gün içerisinde ortaya çıkmış ise ameliyat sonrası komplikasyon veya mortalite olarak değerlendirildi. Hastaların tanıları patolojik olarak doğrulandı. Cerrahi tedavinin sonuçları için hastalara telefon veya poliklinik kontrolleri ile ulaşıldı. Hastalara uygulanan rezeksiyonun tam olup olmadığını değerlendirmek için kontrol gögüs BT veya yüksek çözünürlüklü bilgisayarlı tomografi (YÇBT) çekildi (Şekil1, Şekil 2). Hastalar çalışma ile ilgili olarak bilgilendirildi. Tüm hastalar yaş, cinsiyet, yandaş hastalıklar, semptomlar, sigara öyküsü, tanı yöntemleri, hastalığın yerleșim yeri, yapılan ameliyat, morbidite, mortalite ve cerrahi tedavinin sonuçlar açısından değerlendirildi. Cerrahi tedavinin sonuçlarını değerlendirmede, hasta memnuniyeti temel kriter olarak alınd. Semptomların tamamen veya büyük oranda kaybolması tedavide başarı, semptomların devam etmesi ise başarısızlı olarak değerlendirildi.

\section{BULGULAR}

Olgularda ortalama yaş:44 ( Dağllım: 14-68), kadın/erkek oranı 11/7 idi. Kronik öksürük ve balgam çıkarma en sık görülen semptomu oluşturuyordu. Yedi olguda yandaş hastalık, 2 olguda sigara öyküsü mevcuttu. Bir olgu henüz çocukluk çağında iken 2 olgu erişkin yaşta müracaat etmekle birlikte çocukluk çağından beri şikayetlerinin devam ettiğini ifade ettiler. Olguların hiçbirinde kistikfibrozis veya başka bir doğumsal hava yolu anomalisi, immun yetmezlik ve silierdiskinezi mevcut değildi. Tüm olgularda postenfeksiyöz etyolojinin rol oynadığı düşünülmektedir. Göğüs BT en sık kullanılan tanısal araçtı ( Tablo 1).

Sol alt lob en çok etkilenen akciğer bölgesini oluşturmaktaydı ( Tablo 2). On altı hastada (\%89) tam rezeksiyon, 2 hastada (\%11) tam olmayan rezeksiyon uyguland. En sik sol alt lobektomi yapıldı (Tablo 3). Hiçbir olguda mortalite gözlenmezken, $\% 20(n=4)$ oranında postoperatif morbidite gelişti. İki olguda ekspansiyon kusuru, bir olguda uzamış hava kaçağı ve ekspansiyon kusuru bir olguda ise atelektazi gözlendi. Ortalama takip süresi 30 (Dağılım:5- 65) ay idi. En çok olgu (n=5) 2016 yılında, en az olgu (n=1) 2014 yllında opere edildi (Tablo4). Olguların takibi sonucu cerrahi tedavi başarı oranı \%95 (n=17) olarak saptandl. 
Dadaş E.

Tablo 1: Hastaların Klinik Özellikleri

\begin{tabular}{|lcc|}
\hline Değişkenler & Hasta Sayısı & $\%$ \\
\hline Cinsiyet & 11 & 60 \\
Kadın & 7 & 40 \\
Erkek & & \\
Semptomlar & 9 & 50 \\
$\quad$ Öksürük ve balgam çıkarma & 6 & 33 \\
$\quad$ Hemoptizi & 1 & 5,5 \\
$\quad$ Kronik kuru öksürük & 1 & 5,5 \\
$\quad$ Nefes darlığı & 1 & 5,5 \\
$\quad$ Sı̈ akciğgr enfeksiyonu geçirme & 2 & 11 \\
Sigara Öküsü (Ortalama:17 paket/yıl) & 1 & 5,5 \\
Yandaş Hastalıklar & 1 & 5,5 \\
$\quad$ KAH & 1 & 5,5 \\
HT & 1 & 5,5 \\
$\quad$ KOAH+DM & 1 & 5,5 \\
Trakeal Bronkus & 1 & 5,5 \\
MS & & 66 \\
Ampiyem & 12 & 34 \\
Teşhis Yöntemi & 6 & \\
Göğüs BT & & \\
Göğüs BT+ Bronkoskopi & & \\
\hline
\end{tabular}

KAH: Koroner Arter Hastalı̆ı̆, HT: Hipertansiyon, KOAH: Kronik Obstrüktif Akciğer Hastalığı, DM: Diabetes Mellitus, MS: Multiple Skleroz

Tablo 2: Hastalı̆̆ın Yerleșim Yeri

\begin{tabular}{|lcc|}
\hline Hastalık Lokalizasyonu & Hasta Sayısı & $\%$ \\
\hline Sol alt lob ve Lingula & 3 & 16 \\
Sol alt lob & 3 & 16 \\
Sağ alt lob & 2 & 11 \\
Sağ üst lob & 2 & 11 \\
Sağ üst ve orta lob & 2 & 11 \\
Sağ alt ve orta lob & 2 & 11 \\
Bilateral alt lob & 1 & 5,5 \\
Sağ akciğerde yaygın & 1 & 5,5 \\
Sol akciğerde yaygın & 1 & 5,5 \\
Lingula & 1 & 5,5 \\
\hline
\end{tabular}

Tablo 3: Uygulanan Akciğer Rezeksiyonları

\begin{tabular}{|lcc|}
\hline Rezeksiyon Tipi & Hasta Sayısı & $\%$ \\
\hline Sol alt lobektomi & 4 & 22 \\
Sol alt lobektomi ve lingulektomi & 2 & 11 \\
Sağ alt lobektomi & 2 & 11 \\
Sol alt lobektomi ve LWR & 1 & 5,5 \\
Sağ üst lobektomi & 1 & 5,5 \\
Sağ pnömonektomi & 1 & 5,5 \\
Sol pnömonektomi & 1 & 5,5 \\
Sağ üst apikal segmentektomi & 1 & 5,5 \\
Lingulektomi & 1 & 5,5 \\
Sağ üst bilobektomi & 1 & 5,5 \\
Sağ alt bilobektomi & 1 & 5,5 \\
Orta lobektomi ve üst lob posteriyor SWR & 1 & 5,5 \\
Orta lobektomi ve alt lob anterobazal SWR & 1 & 5,5 \\
\hline
\end{tabular}

LWR: Lingulaya Wedge Rezeksiyon, SWR: Segment Wedge Rezeksiyon 
Tablo 4: Olguların Yıllara Göre Dağılımı

\begin{tabular}{|cc|}
\hline Yıllar Olgu Sayısı & \\
\hline 2012 & 3 \\
2013 & 4 \\
2014 & 1 \\
2015 & 2 \\
2016 & 5 \\
2017 & 3 \\
Toplam & 18 \\
\hline
\end{tabular}

\section{TARTIŞMA}

Çocuklarda, akciğer enfeksiyonlarının tedavisindeki iyileşmeler bronşektazi insidansını ve buna bağlı olarak cerrahi tedaviye olan gereksinimi azaltmıștır. Ancak bu durum gelişmekte olan ülkelerde halen bir sağlık sorunu olmaya devam etmektedir ${ }^{5}$. Gelişmekte olan ülkelerde, bronşektazinin en yaygın nedeni pulmoner enfeksiyonların yetersiz tedavisidir. Ancak akciğer tuberkülozu ve tedavi edilmemiş yabancı cisim gibi diğer nedenlerin de göz önünde tutulması gerekir6 Bagheri ve ark.7, İran'da cerrahi tedavi uyguladıkları 277 hastadan (çocuk ve erişkin) oluşan çalışmalarında bronşektazinin en yaygın nedeninin $(\% 77,6)$ akciğer enfeksiyonlarının yetersiz tedavisi olduğunu bildirmişlerdir. En yaygın hasta yakınması ise yaşam kalitesini bozan ve depresyona yol açan balgamlı öksürüktür8. Nitekim bizim çalıșmamızda, postinfeksiyöz etyoloji tek etyolojik nedeni, kronik öksürük ve balgam çıkarma ise en önde gelen cerrahi endikasyonu oluşturmaktaydı.

Bilgisayarlı tomografinin yaygın olarak kullanımından önce, bronșektazi tanısında en yaygın kullanılan yöntemler direkt grafi ve bronkografi idi. Ancak günümüzde, BT görüntülemenin yüksek kalitesinden dolayı bronkografi kullanılmamaktadır. Gelişmiş BT görüntüleme, cerrahlara iyi anatomik detaylar sağlayarak, cerrahi planlamayı daha iyi yapmalarını mümkün kılar ve genellikle bronkografiye gerek kalmaz ${ }^{9}$. Manyetik rezonans görüntüleme bronșektazi tanı ve takibinde radyasyonsuz görüntüleme yöntemi olma avantajına sahip olmakla birlikte YÇBT tanının doğrulanmasında altın standart yöntemdir ${ }^{10}$. Bizim çalışmamızda tüm hastalarda, YÇBT' ye gerek kalmadan, BT cerrahi planlama için gerekli verileri sağladı. Göğüs cerahisindeki klinik ilerlemelere rağmen, bronşektazide optimal tedavi halen tartışmalıdır6,11. Medikal tedavi yetersiz kaldığı zaman, gögüs hastalıkları kliniklerince, bronșektazi hastalarl, semptomlarda düzelme beklentisi ile bir gögüs cerrahi kliniğine yönlendirilir12. Bizim hastalarımızın önemli bir kısmı sürekli veya tekrarlayan yakınmaları nedeni göğüs hastalıkları kliniklerince yatırılarak takip edilen ve semptomlarında kısmen veya tamamen düzelme beklentisi ile cerrahiye yönlendirilen veya acile hemoptizi şikayetleri ile müracaat eden hastalardan oluşmakta idi.

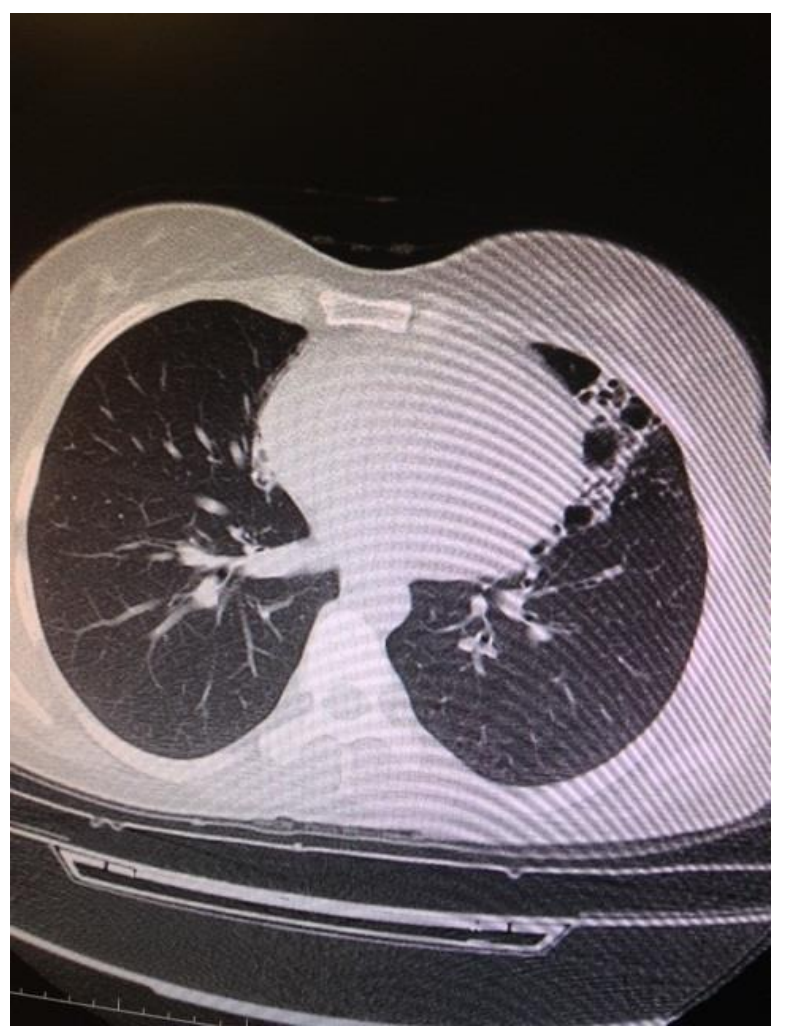

Şekil 1.Linguler segmentteki bronşektazik tutulumu gösteren tomografi kesiti 


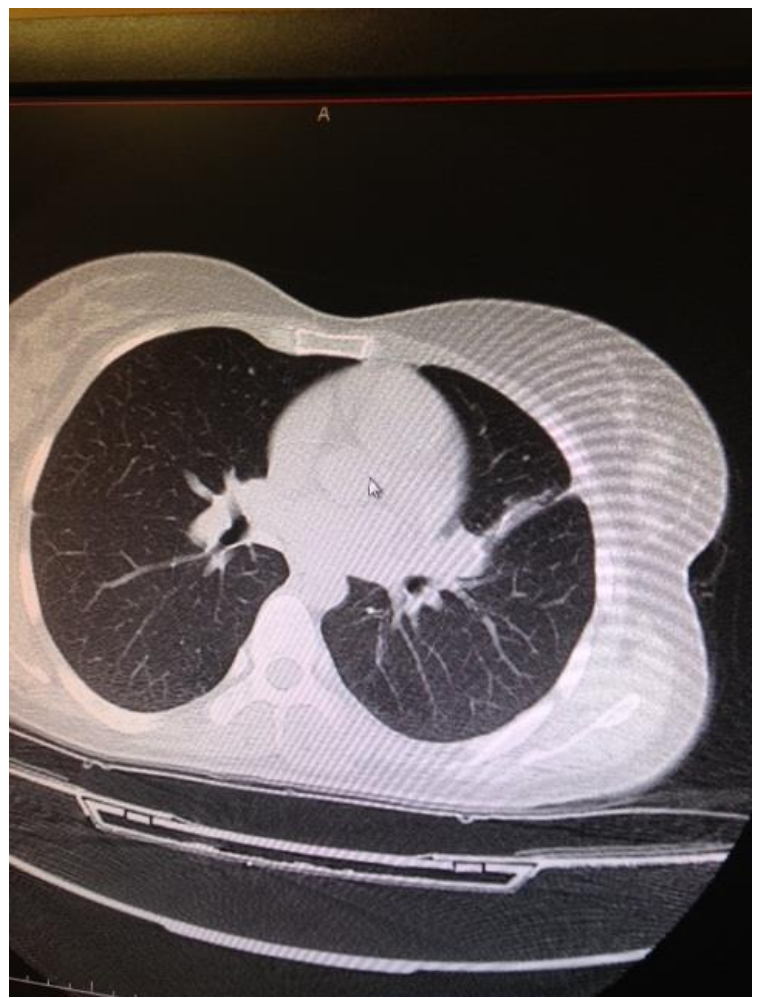

Şekil 2. Aynı olgunun operasyon (lingulektomi) sonrası tomografi kesiti

Bronşektazi cerrahisinde amaç, yaşam kalitesini yükseltmek ve akciğer apsesi, ampiyem ve ciddi hemoptizi gibi komplikasyonlardan korumaktır. Ayrica, progressif bir hastalık olan bronşektazide, hastalık bölgesel iken etkilenmiş parankim segmentlerinin rezeke edilerek sağlam parankimin korunması gerekir ${ }^{2,7,11-}$ 13.Bronşektazide, tam ve akciğer fonksiyonlarını mümkün olduğu kadar çok koruyan anatomik rezeksiyonlar yapılmalıdır. $\mathrm{Bu}$ amaçla her tip rezeksiyon mümkündür. Yeterli akciğer fonksiyonları için en az iki lob veya altısegment korunmalıdır9,14,15. Silindirik olmayan hastalık, balgam kültürü ile kanıtlanmış psödomonas enfeksiyonu ve lokalize olmayan hastalık bronşektazinin cerrahi tedavisi için göreceli kontrendikasyonları oluşturmaktadır ${ }^{10}$. Multisegmental ve iki taraflı tutulumda cerrahi tartışmalıdır. Ancak medikal tedavinin yetersiz kaldığı veya hemoptizi gibi yaşamı tehdit eden durumlarda palyatif cerrahi göz önünde bulundurulmalıdır ${ }^{16}$. Serimizde tam olmayan cerrahi uygulanan 2 hastadan bir tanesinde bilateral alt lob tutulumu olmasına rağmen hemoptizi tarafı olması nedeniyle sol alt lobektomi, diğer hastada ise sağ üst ve orta lobda tutulum olmasına rağmen solunum rezervinin kısıtlı olması nedeni ile orta lobektomi ve üst lob posteriyor segment wedge rezeksiyonu uygulanmıştır.

Prieto ve ark. ${ }^{13}$ çalışmalarında, \%89 oranında tam rezeksiyon uyguladıkları hasta grubunda hastaların \%74'ü asemptomatik hale gelir iken, \%25'inde klinik düzelme sağlamış, \%1'inde ise klinik başarısızlık elde etmişlerdir. Söz konusu çalışmada \%11 tam olmayan rezeksiyon uygulanmış ve bu gruptaki hastalar için, asemptomatik hasta, semptomlarında düzelme olan hasta ve düzelme olmayan hasta oranları sırası ile \%9, \%64 ve \%27 olarak belirtilmiştir. Yine Ötgün ve ark. ${ }^{11}$, çalışmalarında \%24 tam olmayan rezeksiyon uygulamışlardır. Söz konusu çalışmada tam olmayan rezeksiyon grubundaki hastalarin \%15'inde semptomlar tamamen kaybolur iken, \%61'inde semptomlarda düzelme sağlamış, \%23'ünde ise semptomların aynı kaldığı belirtilmiştir. Çalışmamızda, tam olmayan rezeksiyon uygulanan 2 (\%11) hastadan bir hastada tam klinik düzelme sağlanırken diğer hastanın şikayetlerinin uzun dönemde tekrar ortaya çıktığı görüldü.

Tüm hastalarımızda, ameliyat sonrası bronşiyal fistül gelişimini önlemek için aşırı diseksiyondan kaçınıldı ve pnömonektomi uygulanan 2 olguda bronşiyal güdük canlı bir doku (interkostal kas flebi) ile desteklendi. Hiçbir olgumuzda bronşiyal fistül gözlenmedi. Prieto ve ark. ${ }^{13} 119$ hastadan oluşan çalışmalarında canlı doku ile bronş güdügünü desteklemiş ve bir olguda $(\% 0,8)$ fistül sorunu ile karşılaşmışlardır. Kutlay ve ark.nın ${ }^{6}$ çalışmasında ise destek kullanılmamış ve bir olguda $(\% 0,6)$ fistül gelişmiştir. Çalışmamızda 
mortalite gözlenmedi. Morbidite oranımız Şahin ve ark.nın ${ }^{17}$ çalışması ile uyumlu iken (\%20), başarı oranımız ise Kutlay ve ark.nın ${ }^{6}$ sonuçları (\%96),ile uyumlu idi. Son dönemde yapılan bir meta-analiz çalışmasında erişkin grupta cerrahiye bağlı mortalitenin çocuk yaş grubuna göre daha yüksek olduğu saptanmış ve araştırmacılar erişkin grupta diabet ve kalp hastalığı gibi yandaş hastalıkların bundan sorumlu olduğu sonucuna varmışlardır ${ }^{18}$.

Sonuç olarak, bronşektazinin cerrahi tedavisi \%95 gibi yüksek başarı ve kabul edilebilir mortalite- morbidite oranları ile etkili ve güvenli bir tedavi seçeneğidir. Hemoptizi gibi hayatı tehdit edici komplikasyonları kontrol altına alır ve hasta memnuniyeti açısından tatmin edici sonuçlar sağlar.

Çıkar Çatışması Beyanı: Yazarlar çıkar çatışması olmadığını bildirmişlerdir.

Finansal Destek: Bu çalışma her hangi bir fon tarafından desteklenmemiştir.

Declaration of Conflicting Interests: The authors declare that they have no conflict of interest.

Financial Disclosure: No financial support was received.

\section{KAYNAKLAR}

1. Bilton D. Update on non-cystic fibrosis bronchiectasis. Curr Opin Pulm Med. 2008; 14:595-9.

2. Subotic DR. Indications and results of resection surgical approach in localized type of bronchiectasis. Acta Chir Lugosl. 2008; 55:75-9.

3. Balci AE, Balci TA, Eren S, et al. Bronşektazide operasyonun rolü: Cerrahi ve medikal tedavinin karşılaştırması. Turk Gogus Kalp Dama. 2002; 10:95101.

4. Giovannetti R, Alifano M, Stefani A, et al. Surgical treatment of bronchiectasis: early and long-term results. Interact Cardiovasc Thorac Surg. 2008; 7:60912.

5. Ashour M, Al-Kattan K, Rafay MA, et al. Current surgical therapy for bronchiectasis. World J Surg. 1999; 23:1096-104.
6. Kutlay H, Cangir AK, Enön S, et al. Surgical treatment in bronchiectasis: analysis of 166 patients. Eur J Cardiothorac Surg. 2002; 21:634-7.

7. Bagheri R, Haghi SZ, Fattahi Masoum SH, et al. Surgical management of bronchiectasis: analysis of 277 patients. Thorac Cardiovasc Surg. 2010; 58:291-4.

8. Hodder RV, Cameron R, Todd TRJ. Thoracic Surgery: Bacterial infections, 2 nd edn. New York: Churchill Livingstone, 1995: 43-70.

9. Sırmalı M, Karasu $S$, Türüt $H$, et al. Surgical management of bronchiectasis in childhood. Eur J Cardiothorac Surg. 2007; 31:120-3.

10. Gallucci M, di Palmo E, Berteli L, et al. A pediatric disease to keep in mind: diagnostic tools and management of bronchiectasis in pediatric age. Ital J pediatr. 2017; 43:117. [Open access]

11. Ötgün I, Karnak I, Tanyel FC, et al. Surgical treatment of bronchiectasis in children. J Pediatr Surg. 2004; 39:1532-6.

12. Yüncü G, Ceylan KC, Sevinc $S$, et al. Functional results of surgical treatment of bronchiectasis in a developing country. Arch Bronconeumol. 2006; 42:183-8.

13. Prieto D, Bernardo J, Matos MJ, et al. Surgery for bronchiectasis. Eur J Cardiothorac Surg. 2001; 20:1923.

14. Balkanlı K, Genç O, Dakak M, et al. Surgical management of bronchiectasis: analysis and short-term results in 238 patients. Eur J Cardiothorac Surg. 2003; 24:699-702.

15. Neves PC, Guerra M, Ponce P, et al. Noncystic fibrosis bronchiectasis. Interact Cardiovasc Thorac Surg. 2011; 13:619-25.

16. Fujimoto T, Hillejan L, Stamatis G. Current strategy for surgical management of bronchiectasis. Ann Thorac Surg. 2001; 72:1711-5.

17. Şahin A, Meteroğlu F, Kelekçi S, et al. Surgical Outcome of Bronchiectasis in Children: Long Term Results of 60 Cases. Klin Padiatr. 2014; 226: 233-7.

18. Fan LC, Liang S, Lu HW, et al. Efficiency and safety of surgical intervention to patients with Non- Cystic Fibrosis bronchiectasis: a meta-analysis. Sci Rep. 2015; 5:17382. [Open access] 